\title{
Efficiency Enhancement of Nanoporous Silicon/Polycrystalline-Silicon Solar Cells by Application of Trenched Electrodes
}

\author{
Kuen-Hsien Wu and Chia-Chun Tang \\ Department of Electro-Optical Engineering, Southern Taiwan University of Science and Technology, Tainan 710, Taiwan \\ Correspondence should be addressed to Kuen-Hsien Wu; khwu@mail.stust.edu.tw
}

Received 20 July 2014; Accepted 27 August 2014; Published 7 September 2014

Academic Editor: Teen-Hang Meen

Copyright (C) 2014 K.-H. Wu and C.-C. Tang. This is an open access article distributed under the Creative Commons Attribution License, which permits unrestricted use, distribution, and reproduction in any medium, provided the original work is properly cited.

Trenched electrodes were proposed to enhance the short-circuit current and conversion efficiency of polycrystalline-silicon (polySi) solar cells with nanoporous silicon (NPS) surface layers. NPS films that served as textured surface layers were firstly prepared on heavily doped $\mathrm{p}^{+}$-type (100) poly-Si wafers by anodic etching process. Interdigitated trenches were formed in the NPS layers by a reactive-ion-etch (RIE) process and $\mathrm{Cr} / \mathrm{Al}$ double-layered metal was then deposited to fill the trenches and construct trenchedelectrode-contacts (TEC's). Cells with TEC structures (called "TEC cells") obtained 5.5 times higher short-circuit current than that of cells with planar electrode contacts (called "non-TEC cells"). Most significantly, a TEC cell achieved 8 times higher conversion efficiency than that of a non-TEC cell. The enhanced short-circuit current and conversion efficiency in TEC cells were ascribed to the reduced overall series resistance of devices. In a TEC cell, trenched electrodes provided photocurrent flowing routes that directly access the poly-Si substrates without passing through the high resistive NPS layers. Therefore, the application of NPS surface layers with trenched electrodes is a novel approach to development of highly efficient poly-Si solar cells.

\section{Introduction}

Because of the high-cost and shortage of single-crystallinesilicon (c-Si) wafers, polycrystalline-silicon (poly-Si) had recently become one of the main materials for mass production in solar cell manufacturing industries. Nevertheless, the poly-Si cells are less efficient in power conversion than the cSi ones due to their lower silicon purity. Efficiency improvement had been an essential task in the development of poly-Si cells. Generally, the light-absorption spectra of poly-Si range primarily from visible light to near-infrared (NIR). Therefore, increasing the absorption efficiency in the solar irradiance spectra, especially the short-wavelength ranges, is one of the key approaches to promote the conversion efficiency of polySi cells.

Well-known for its photoluminescence and electroluminescence characteristics at room temperature [1-3], porous silicon (PS) has a variety of unique physical and chemical properties. Especially, it was regarded as a wide-band gap semiconductor due to the quantum-size effect [4]. PS has higher absorption efficiency for short-wavelength light than $\mathrm{c}-\mathrm{Si}$ and poly-Si. Therefore, the combination of PS with poly$\mathrm{Si}$ becomes a promising alternative in the development of low-cost and high-efficiency solar cells [5-7].

Among the various PS structures, nanoporous silicon (NPS) is great potential for solar cell applications owing to several advantageous characteristics, including the light absorption spectra close to the solar irradiance and low lightreflection coefficient from its effective textured structures $[8,9]$. Unfortunately, the high resistivity of this material is apt to cause high series resistance of devices and result in poor conversion efficiency. In this work, trenched-electrodecontact (TEC) structures were proposed in the fabrication of NPS/poly-Si solar cells. Via TEC's, photocurrent can flow without passing the highly resistive NPS layers. As a result, 


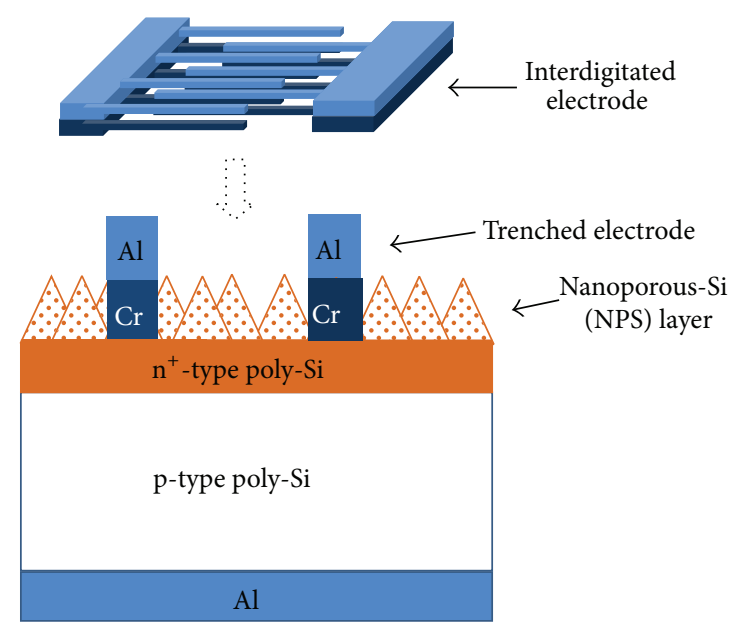

FIGURE 1: The schematic structure of a NPS/poly-Si solar cell with trenched electrodes. Interdigitated Cr/Al electrodes were also shown above the device.

the overall series resistance of devices decreases and thus the conversion efficiency of cells increases.

\section{Materials and Methods}

According to the related studies, uniform NPS layers were much easily prepared on heavily doped Si substrates [10]. Therefore, to prepare NPS layers, $\mathrm{n}^{+}$-type poly-Si surface layers were firstly formed on p-type poly-Si wafers by an iterative-diffusion doping technique using $\mathrm{POCL} / \mathrm{O}_{2}$ at $850^{\circ} \mathrm{C}$. After five times of diffusion processes, an $\mathrm{n}^{+}-$ poly-Si surface layer with resistivity of $0.027 \Omega-\mathrm{cm}$ can be obtained. Then NPS films were prepared on the heavilydoped $\mathrm{n}^{+}$-poly-Si layers by an anodic etching process. The anodization was carried out under etching parameters of $\mathrm{HF}: \mathrm{C}_{2} \mathrm{H}_{5} \mathrm{OH}: \mathrm{H}_{2} \mathrm{O}=18: 1: 1$ at a current density of $5 \mathrm{~mA} / \mathrm{cm}^{2}$. Thereafter, interdigitated trenches were formed in the NPS layers by a reactive-ion-etch (RIE) process by using a metal mask. A gas mixture of $\mathrm{CF}_{4} / \mathrm{O}_{2}$ was used as the etchant gas. The flow rates employed were $25 \mathrm{sccm}$ of $\mathrm{CF}_{4}$ and $3 \mathrm{sccm}$ of $\mathrm{O}_{2}$ under a pressure of 100 mTorr. The power was held at $100 \mathrm{~W}$ and the etching time was $30 \mathrm{~s}$. The estimated etch rate for NPS and poly-Si is about $10 \mathrm{~nm} / \mathrm{s}$ and $0.5 \mathrm{~nm} / \mathrm{s}$, respectively. Because the etch rate of NPS is 20 times higher than that of poly-Si, the bottom of the trench will approximately reach the poly-Si layer at the etching end for a controlled etching time. Finally, by using the same metal mask, double-layered metals of $\mathrm{Cr} / \mathrm{Al}$ were deposited to fill the trenches by e-beam evaporation and construct the TEC structures. Figure 1 illustrated the schematic structure of the developed NPS/poly-Si cell with a TEC. The shapes of $\mathrm{Cr} / \mathrm{Al}$ interdigitated electrodes were also shown above the device. The cell's area is about $2 \mathrm{~cm} \times 2 \mathrm{~cm}$. The thickness of NPS and $\mathrm{n}^{+}$-poly-Si layer is about $200 \mathrm{~nm}$ and $5 \mu \mathrm{m}$, respectively. The TEC had metal fingers of $0.2 \mathrm{~mm}$ in width with a space of $0.5 \mathrm{~mm}$ between two fingers.

The surface morphology and TEC structures of the NPS/poly-Si cells were observed by field-emission scanning electron microscopy (FE-SEM) and an optical microscope
(OM), respectively. A four-point probe (MODEL 280Si, Four Dimension Inc.) was used to measure the resistivity of polySi. Optoelectronic characteristics of devices were analyzed by a photoresponse measurement system with a TRIAX320 spectrometer. A Solar Simulator (Newport M-91190A) was used to measure the current-voltage characteristics and the conversion efficiency of devices.

\section{Results and Discussion}

Figure 2 showed the top and cross-sectional view of SEM images of the formed NPS layers on poly-Si substrates. It can be observed that the as prepared NPS layer was with uniformly distributed Si nanoparticles of about $8 \sim 10 \mathrm{~nm}$ in sizes. Figure 3 showed the local OM images of the formed trenched structures on the NPS/poly-Si before and after metal contacts. The dark-brown and light-brown areas denoted the NPS and poly-Si regions, respectively, as shown in Figure 3(a). We can observe that trenches were formed in the NPS surface layers after the RIE process. As shown in Figure 3(b), the trenches were filled with $\mathrm{Al} / \mathrm{Cr}$ metals (the green areas) after e-beam evaporation, indicating the TEC structures were successfully constructed without covering the NPS regions.

Figure 4 illustrated the photoresponse spectra of polySi with and without a NPS surface layer. It was apparent that a NPS/poly-Si structure achieved higher and broader photoresponse than that of a poly-Si one without a NPS layer. Estimated from the Tauc's plot, the bandgap energy $\left(E_{g}\right)$ of the prepared NPS was about $2.0 \mathrm{eV}$ which is larger than that of poly-Si $(1.1 \mathrm{eV})$. Because the corresponding cutoff wavelength $\lambda_{c}(\mathrm{~nm})=1240 / E_{g}=1240 / 2.0 \approx 620 \mathrm{~nm}$, the enhanced short-wavelength responses within $400 \sim 700 \mathrm{~nm}$ were thought to be resulting from the light-absorption of NPS layers. Besides, the enhanced long-wavelength response above $700 \mathrm{~nm}$ was owing to the effective textured structures of NPS surface layers that reduced the optical reflection and thus increased light-absorption efficiency in the visible to NIR ranges. 


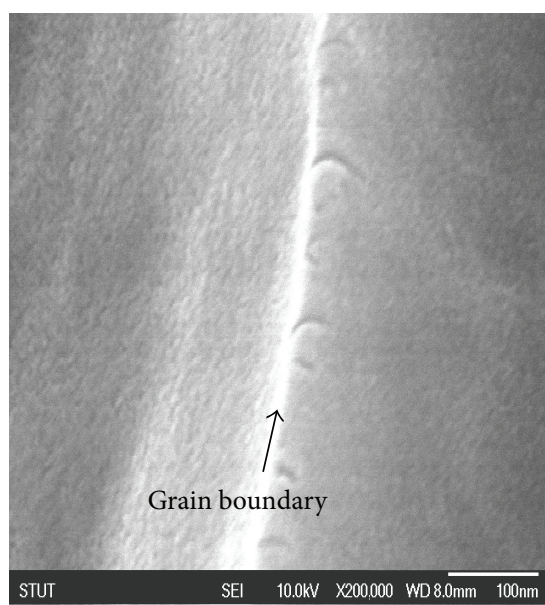

(a)

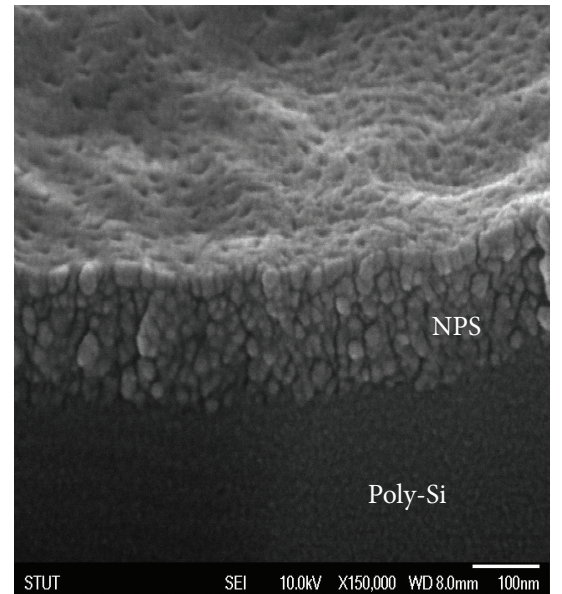

(b)

Figure 2: (a) The top view and (b) the cross-sectional view of SEM images of the developed NPS/poly-Si structure.

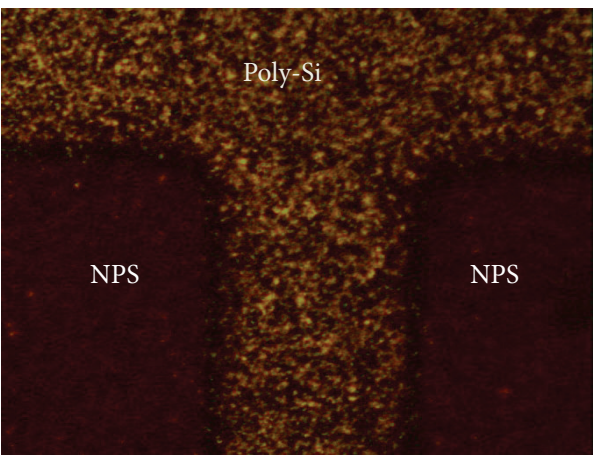

(a)

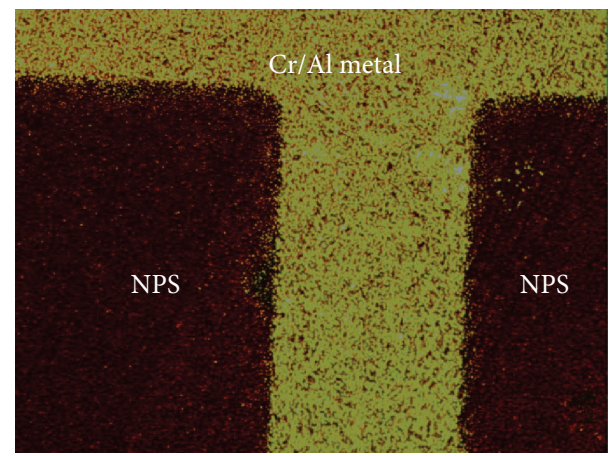

(b)

FIGURE 3: The local images of the formed trench structures on NPS (a) before and (b) after metal contacts, observed by an optical microscope.

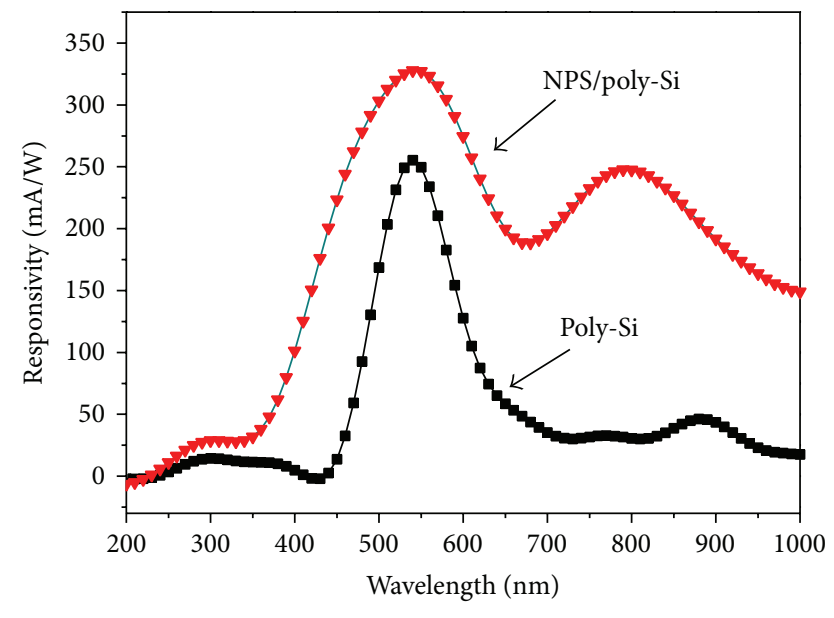

FIGURE 4: Photoresponse spectra of the NPS/poly-Si cell and the poly-Si cell.

Figure 5 showed the photocurrent and dark current of the NPS/poly-Si cells with and without TEC structures.
The photocurrent was measured under illumination of $100 \mathrm{~mW} / \mathrm{cm}^{2}$ at AM1.5 using a solar simulator. Cells with TEC's (TEC cells) got larger dark current and photocurrent than those of cells without TEC's (non-TEC cells), indicating that the overall resistance of a TEC cell was lower than that of a non-TEC cell. The estimated average resistance is $60 \Omega$ and $260 \Omega$ for the TEC cell and the non-TEC cell, respectively. The reduced overall resistance of devices is ascribed to the TEC structures. Via TEC's, the main current of cells can directly access devices, instead of flowing through the high resistive PS layers.

Current-voltage characteristics of NPS/poly-Si cells with and without TEC, measured by a solar simulator, were shown in Figure 6. From the curves in this figure, we can infer that a TEC cell had much lower series resistance than that of a non-TEC one, as a result of decreased contact resistance of devices by using TEC. The measured parameters of currentvoltage characteristics were summarized in Table 1 . It is highly important to note that a TEC cell achieved a shortcurrent of $11.77 \mathrm{~mA}$ and conversion efficiency of $4.1 \%$, which was about 5 times and 8 times larger than those of a non-TEC one, respectively. 
TABLE 1: Parameters of current-voltage characteristics of NPS/polySi cells with and without TEC structures. The devices were measured by a solar simulator under irradiation of $P_{L}=100 \mathrm{~mW} / \mathrm{cm}^{2}$ at AM1.5, with an irradiated area of $0.5 \mathrm{~cm}^{2}$.

\begin{tabular}{lcccc}
\hline Devices & $I_{\mathrm{sc}}(\mathrm{mA})$ & $V_{\mathrm{oc}}(\mathrm{V})$ & $\mathrm{FF}$ & $\eta \%$ \\
\hline Non-TEC Cell & 2.42 & 0.41 & 0.26 & 0.52 \\
TEC cell & 11.77 & 0.48 & 0.36 & 4.10 \\
\hline
\end{tabular}

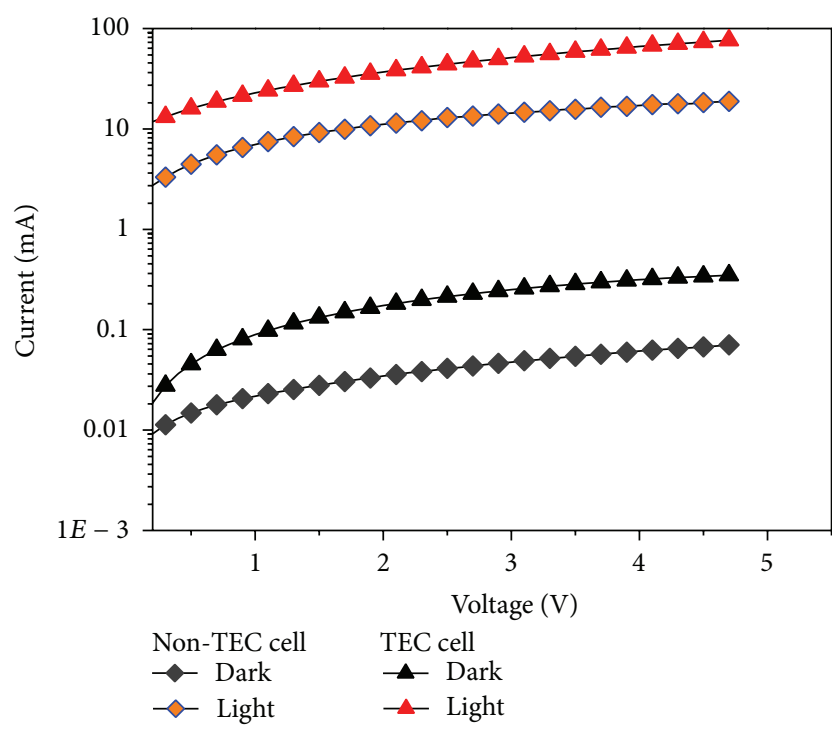

FIgURE 5: Photocurrent and dark current of the NPS/poly-Si cells with and without a trenched-electrode-contact (TEC) structure. The photocurrent is measured by a solar simulator under $P_{L}=$ $100 \mathrm{~mA} / \mathrm{cm}^{2}$ at AM1.5.

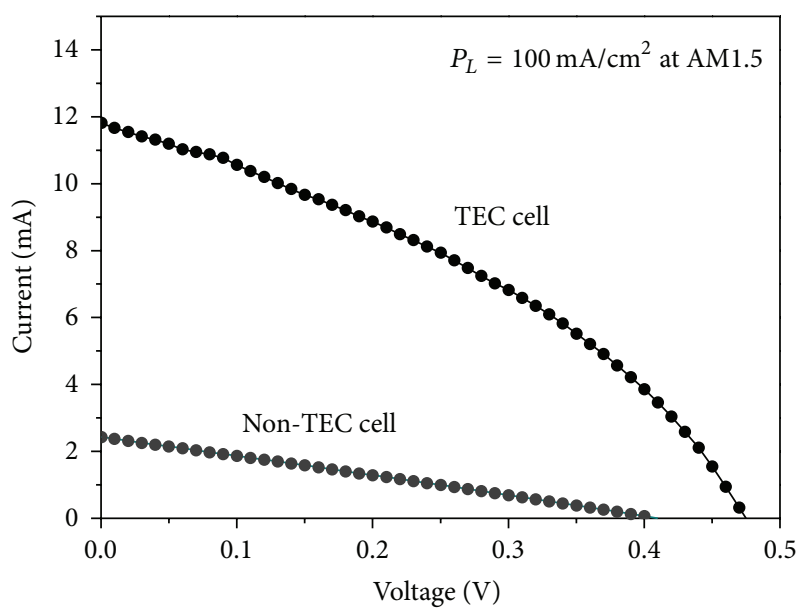

FIGURE 6: Current-voltage characteristics of the NPS/poly-Si cells with and without a trenched-electrode-contact (TEC) structure, measured by a solar simulator under $P_{L}=100 \mathrm{~mA} / \mathrm{cm}^{2}$ at AM1.5.

\section{Conclusions}

TEC structures were successfully fabricated in NPS/polySi solar cells by means of a RIE process followed a metaldeposition step by e-beam evaporation via a single metal mask. Experimental results demonstrated that TEC structures greatly reduced the overall series resistance of a NPS/ poly-Si cell and effectively increased the conversion efficiency of the cell. Therefore, combination of NPS with TEC has high potential in the development of low-cost poly-Si solar cells with high conversion efficiency.

\section{Conflict of Interests}

The authors declare that there is no conflict of interests regarding the publication of this paper.

\section{Acknowledgment}

The authors acknowledge financial support from the Ministry of Science and Technology, Taiwan, under Contract no. NSC 100-2221-E-218-030.

\section{References}

[1] R. L. Smith and S. D. Collins, "Porous silicon formation mechanisms," Journal of Applied Physics, vol. 71, no. 8, pp. R1-R22, 1992.

[2] Y. Watanabe, Y. Arita, T. Yokoyama, and Y. Igarashi, "Formation and properties of porous silicon and its application," Journal of the Electrochemical Society, vol. 122, no. 10, pp. 1351-1355, 1975.

[3] V. Parkhutik, "Porous silicon - mechanisms of growth and applications," Solid-State Electronics, vol. 43, no. 6, pp. 1121-1141, 1999.

[4] M. I. J. Beale, J. D. Benjamin, M. J. Uren, N. G. Chew, and A. G. Cullis, "An experimental and theoretical study of the formation and microstructure of porous silicon," Journal of Crystal Growth, vol. 73, no. 3, pp. 622-636, 1985.

[5] V. Y. Yerokhov and I. I. Melnyk, "Porous silicon in solar cell structures: a review of achievements and modern directions of further use," Renewable \& Sustainable Energy Reviews, vol. 3, no. 4, pp. 291-322, 1999.

[6] S. Strehlke, D. Sarti, A. Krotkus, K. Grigoras, and C. LévyClément, "The porous silicon emitter concept applied to multicrystalline silicon solar cells," Thin Solid Films, vol. 297, no. 1-2, pp. 291-295, 1997.

[7] P. Vitanov, M. Kamenova, N. Tyutyundzhiev, M. Delibasheva, E. Goranova, and M. Peneva, "High-efficiency solar cell using a thin porous silicon layer," Thin Solid Films, vol. 297, no. 1-2, pp. 299-303, 1997.

[8] P. Menna, G. di Francia, and V. la Ferrara, "Porous silicon in solar cells: a review and a description of its application as an AR coating," Solar Energy Materials and Solar Cells, vol. 37, no. 1, pp. 13-24, 1995.

[9] V. M. Bright, E. S. Kolesar, and D. M. Sowders, "Reflection characteristics of porous silicon surfaces," Optical Engineering, vol. 36, pp. 1088-1093, 1997.

[10] M.-L. Lin, Y.-C. Lin, K.-H. Wu, and C.-P. Huang, "Preparation of oxidized nano-porous-silicon thin films for ultra-violet optical-sensing applications," Thin Solid Films, vol. 529, pp. 275277,2013 

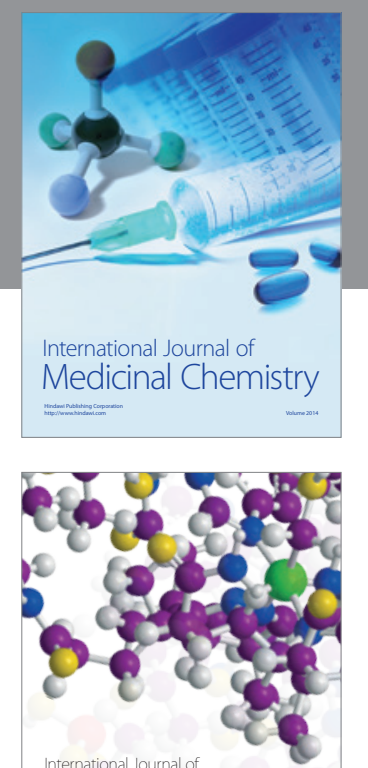

\section{Carbohydrate} Chemistry

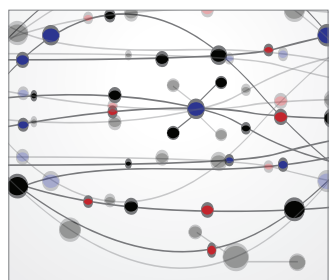

The Scientific World Journal
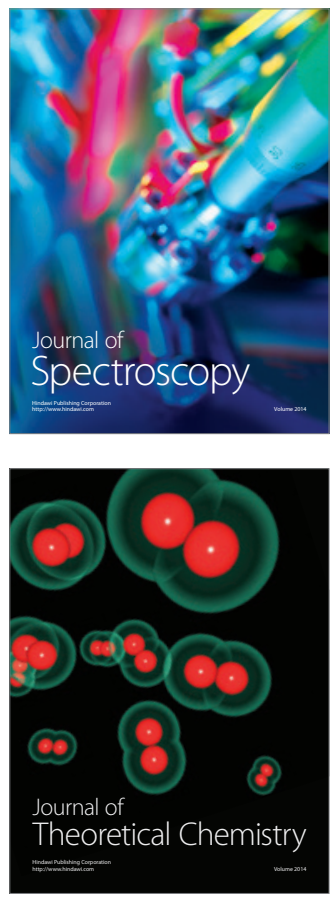
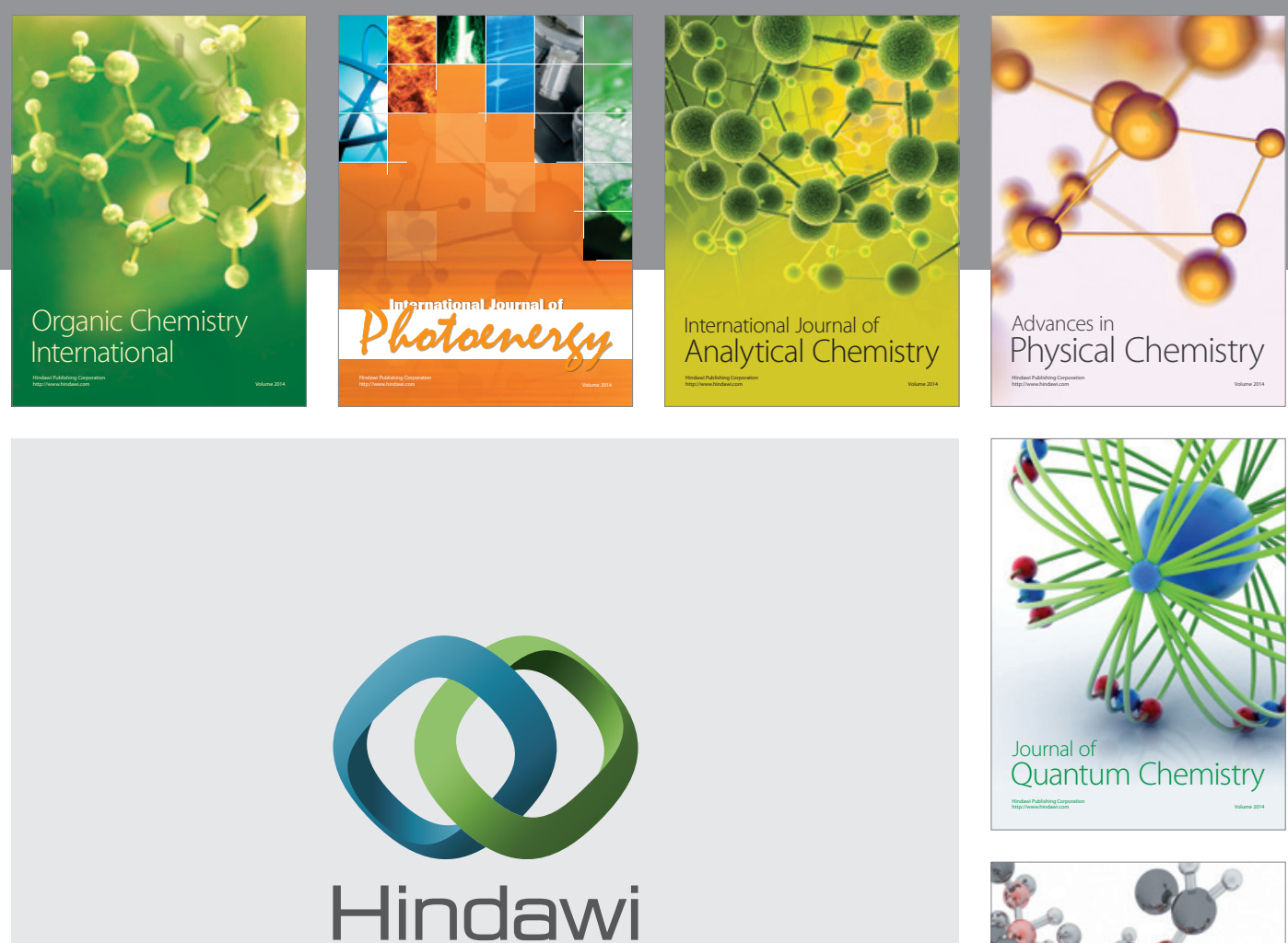

Submit your manuscripts at

http://www.hindawi.com

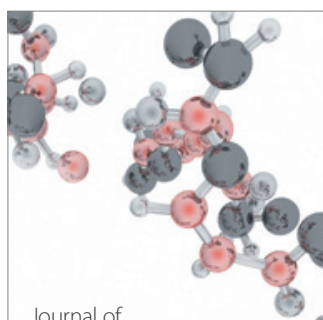

Analytical Methods

in Chemistry

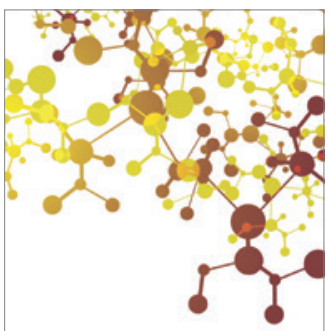

Journal of

Applied Chemistry

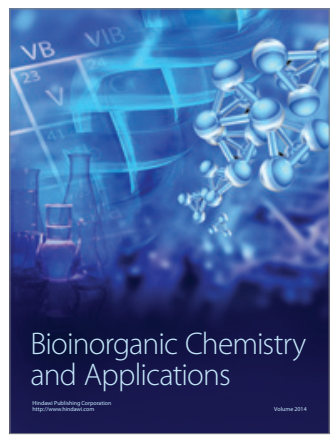

Inorganic Chemistry
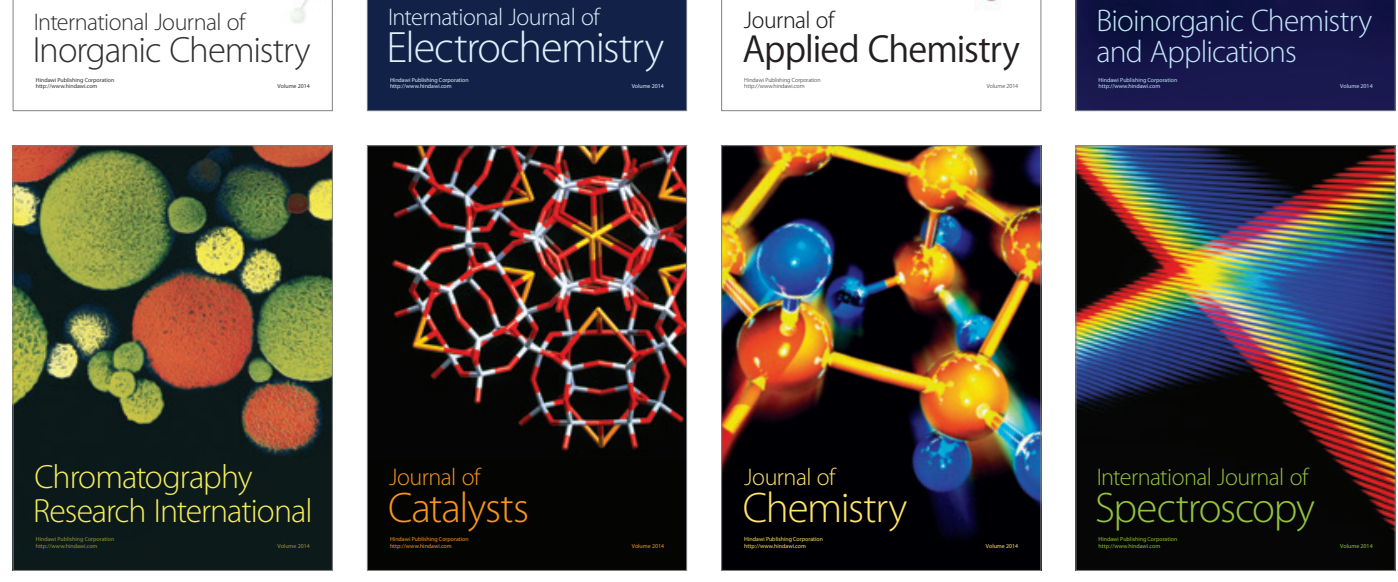